\title{
Axial Dispersion of Gas and Solid Phases in a Gas-Solid Packed Column at Trickle Flow
}

\author{
A W M ROES and W P M VAN SWAAIJ \\ Department of Chemical Engineening, Twente University of Technology, $P O$ Box 217, Enschede \\ (The Netherlands)
}

(Received 1 June 1978, in final form 25 October 1978)

\section{Abstract}

Axial dispersion of gas and solid phases in a gas-solid packed column at trickle flow. a promising new countercurrent operation, was evaluated using residence time distribution (RTD) experiments. The column was packed with dumped Pall rings, the gas phase was air at ambient conditions and the solid was a porous catalyst carrier.

The RTD experiments for the solid phase were carried out using the "perfect pulse method", while for the gas phase the "imperfect pulse method" was used. The model parameters were calculated by the methods of moments and various parameter optimization methods.

At a given solid flow rate axial dispersion of the gas phase decreases with increasing gas velocity and is strongly dependent upon solvd mass flux Axial dispersion of the solid phase is approximately independent of the gas velocity and it is reduced if the solid mass flux is increased For conditions of practical importance, 2 - 5 and 5 - 15 Pall ring layers correspond to the height of a muxing unit in the gas and solid phase, respectively.

\section{INTRODUCTION}

Trickle flow of more or less fluidized solid particles through a packed column seems to be a promising countercurrent operation in the chemical industry, offering interesting heat and mass transfer properties.

In the trickle-flow process a swarm of particles flows in trickles through a packing, while a gas flows upwards countercurrently.
The packing redistributes and carries the solid, facilitating mass transfer, while the axial mixing of the gas and solid is reduced.

Applications may lie in separation processes, based on different adsorption properties of the components, and in chemical reactors where the unconverted reactant may be transported back to the reaction zone, or where reaction products are removed from the reaction zone with the adsorbing solid.

In a previous paper [1] gas-solid trickle flow was compared with other gas-solid countercurrent operations and it was concluded that trickle flow may have advantages over spray columns, moving beds and multistage fluid beds. From experiments with a cracking catalyst it was concluded that the trickle flow of particles through packings exhibits sumilar behaviour to gas-liquid trickle flow. Loading and flooding occurs and hold-up can be split into dynamic or operating hold-up and static hold-up. In gas-liquid packed columns the packing carries all the liquid; in gas-solid trickle flow the packing carres up to $50 \%$ of the dynamic hold-up so that in this case a low pressure drop is obtained.

It clearly follows from many theoretical investigations $(e g$ refs. 2,3$)$ that the axial mixing of both phases in countercurrent operations is very disadvantageous for mass transfer because of the reduction in the driving force for mass transfer. If the number of true mass transfer units is large, axial mixing soon becomes a limiting factor for column performance. The mass transfer for a gassolid packed column at trickle flow was found to be large the height of a true mass transfer unit is usually smaller than $01 \mathrm{~m} \mathrm{[4].} \mathrm{In} \mathrm{this}$ 
situation the axial mixing of both phases is important.

The present investigation deals with the axial mixing of both gas and solid phases in a packed column at trickle flow. As is usually done, the extent of the axial mixing was determined with residence time distribution (RTD) measurements for both phases. The axıally dispersed plug-flow model [5] was used to describe the degree of axial mixing.

A common technique to evaluate the model parameters is to measure the response of a system to a pulse injection which is assumed to be a perfect delta function. For practical reasons this simplified technique had to be applied for the determination of the dispersion of the solid phase.

Since it is often very difficult to approximate the perfect delta function, Aris [6] introduced the imperfect pulse technique where the response of the system is measured continuously over two planes downstream of the injection plane. Aris (see also ref. 7) showed that the first and second moments around the origin of the response curves of the system to any input injection could be used to determine the model parameters. Bischoff later generalized this technique and showed that it could be used in any stable linear system [8]. For the RTD measurements in the gas phase this imperfect pulse technique was followed.

\section{DETERMINATION OF MODEL PARAMETERS}

Two-phase countercurrent processes may be described by a model employing plug flow and axial dispersion in both phases and an interphase mass transfer. More complex mixing models have been discussed for one phase only, but no solutions for two-phase systems are avallable.

Since the tracers were present in one phase only the above mathematical model reduces to the one-dimensional dispersed plug-flow model [5] for both phases.

The mathematical formulation in dimensionless form is represented by the partial differential equation

$\frac{\partial C}{\partial \theta}=\frac{1}{\operatorname{Pe}} \frac{\partial^{2} C}{\partial \xi^{2}}-\frac{\partial C}{\partial \xi}$
The purpose of the present investigation is the determination of the mean residence time and the Peclet number, often called the Bodenstein number when the characteristic length equals the packing drameter. The Bodenstein numbers are defıned by eqns. (2) and (3):

gas phase

$\mathrm{Bo}_{\mathrm{g}}=\frac{u_{\mathrm{g}} d_{\mathrm{p}}}{\epsilon D_{\mathrm{g}}}=\mathrm{Pe}_{\mathrm{g}} \frac{d_{\mathrm{p}}}{L_{2}-L_{1}}$

solid phase

$\mathrm{Bo}_{\mathrm{s}}=\frac{u_{\mathrm{s}} d_{\mathrm{p}}}{\beta D_{\mathrm{s}}}=\mathrm{Pe}_{\mathrm{s}} \frac{d_{\mathrm{p}}}{L}$

The Bodenstein number can be determined from either back-mixing or RTD experiments [3]. The latter method was used in the present investigations. As already mentioned in the introduction we considered the input for the solid phase to be a perfect delta function, while the imperfect pulse technique was used for the gas phase. This is shown schematically in Fig. 1.

Solid tracer was injected at the inlet and detected at the outlet. Since solid mixing in the entrance and outlet zones has been assumed to be negligible, closed-closed boundary conditions [5] were applied. Because the response of the column for the gas phase was measured within the packing, the measuring section for this situation was assumed to be open-open for dispersion [5] . Appendix A gives the intial and boundary conditions for both situations.

The methods to determine the model parameters may be divided into parameter optimization methods and those using the

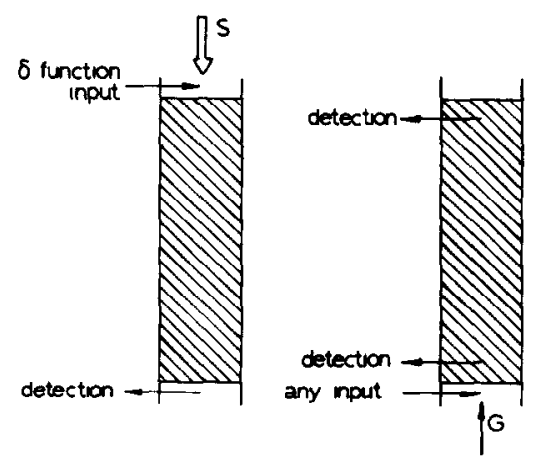

Fig 1 Experimental scheme of injection/detection techniques 
moments of the response curves. With the first methods the parameters are optımızed in such a way that the theoretical model gives the best fit to the experimental data.

For the axially dispersed plug-flow model with closed-closed boundary conditions the response of the system to a perfect delta function has been derived by Otake and Kuniguta [9] (see also ref. 10). This expression is given in Appendix A. For the timedomain optimization the output signal was furst normalized (surface area under response curve made equal to unity). After that, the optimal values of $\mathrm{Bo}_{\mathrm{s}}$ and $\tau_{\mathrm{s}}$ were found which minimize the sum of the squares of the differences between the measured and calculated values. The Bodenstein number and the mean residence time can also be found from the moments around the origin of the output signal. Van der Laan has given the mathematical expressions [11] (see Appendix A).

The transfer function in the time domain for the dispersed plug-flow model with openopen boundary conditions is given in Appendix A, eqn. (A16) (G van Straten, private communication). For the imperfect pulse technique the model parameters can be obtained by numencal convolution $[5,12]$. An alternative way to evaluate the parameters is to transfer the normalized RTD data to the Laplace or frequency domain where the transfer function can be calculated on dividing the transferred output signal by the transferred input signal.

Laplace or s domain

$\bar{F}(s)=\frac{\bar{C}_{\text {out }}(s)}{\bar{C}_{\mathrm{m}}(s)}$

frequency domain

$\hat{F}(j \omega)=\frac{\hat{C}_{\text {out }}(j \omega)}{\hat{C}_{\text {in }}(j \omega)}$

Michelsen and $\varphi$ stergaard [13] and Clements [14] have given mathematical expressions for the transfer functions $\bar{F}(s)$ and $\hat{F}(\mathrm{j} \omega)$ for the dispersed plug-flow model (see Appendix A). The Bodenstein number and the mean residence time can be evaluated from a best fit on the transfer function in the same way as described above.

Four other methods for parameter estimation have been given by Michelsen and $\emptyset$ ster- gaard [13]. They introduced the following functions.

$$
\begin{aligned}
& U_{0}(s)=\ln \bar{F}(s) \\
& U_{1}(s)=-\frac{\mathrm{d} U_{0}(s)}{\mathrm{d} s}=\frac{1}{\bar{F}(s)} \frac{\mathrm{d} \bar{F}(s)}{\mathrm{d} s} \\
& U_{2}(s)=\frac{1}{\bar{F}(s)} \frac{\mathrm{d}^{2} \bar{F}(s)}{\mathrm{d}^{2}}-\left[\frac{1}{\bar{F}(s)} \frac{\mathrm{d} \bar{F}(s)}{\mathrm{d} s}\right]^{2}
\end{aligned}
$$

and derived expressions for (6) - (8) in terms of the model parameters (see Appendix A) $U_{0}(s)$ can be deduced from experimental data via eqn. (4). To avoid numencal differentiation for the evaluation of $U_{1}(s)$ and $U_{2}(s)$ they introduced the weighted moments, which involve numencal integration of the experumental RTD data [13] From the welghted moments, $U_{1}(s)$ and $U_{2}(s)$ can be evaluated. Michelsen and $\varphi$ stergaard [13] and Gunn [15] introduced graphical techniques to determine the mean residence time and the Bodenstein number (see Appendix A).

We also used the method of moments around the ongin to calculate the model parameters. Aris [6] has given mathematical expressions for the model parameters in terms of these moments (see Appendux A).

\section{EXPERIMENTAL SYSTEM}

Figure 2 shows the experimental set-up. Air enters $I_{1}$, a $1.00 \mathrm{~m}$ long column with an internal diameter of $0.075 \mathrm{~m}$, passes through the packing and leaves the column via a disengaging section through a cyclone where the entrained particles are collected. The column is connected to a fluid bed via a Perspex section containing three valves. From the fluid bed a dense gas-solid mixture is transported pneumatically via two venturis through risers $R_{1}$ and $R_{2}$ to the cyclones on top of the column. Solid enters the column via the diplegs of the cyclones. To ensure a good initial distribution, a layer of about $0.05 \mathrm{~m}$ of Pall rings is inserted in the disengaging section. The particles flow through the packing and the Perspex section to the fluid bed which is maintained just above minimum bubbling conditions.

The column was filled with dumped Pall rings. The properties of the packing are listed in Table 1. 


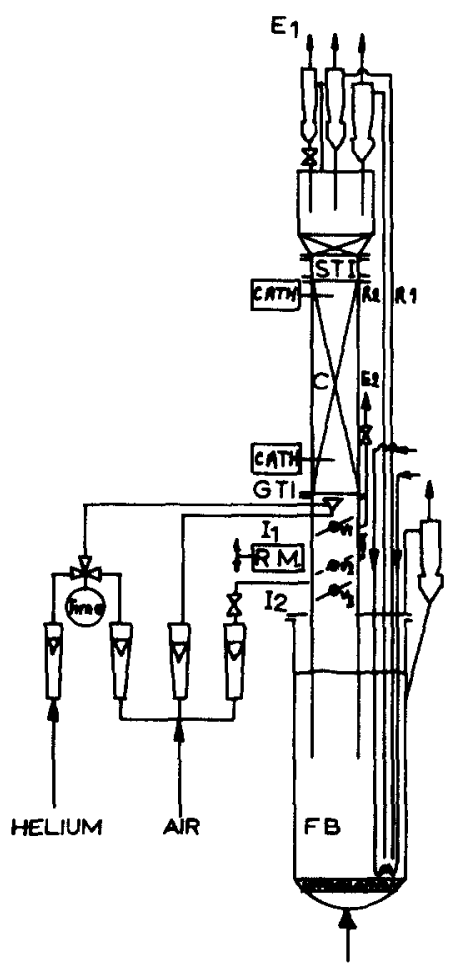

Fig 2 Experimental arrangement for measurement of gas- and solid-phase dispersion $\mathrm{C}$, column, CATH, catharometer, $E_{1}, E_{2}$, gas outlet, FB, fluid bed, GTI, gas tracer injectıon, $I_{1}, I_{2}$, gas inlets, $R M$, reflectometer, $R_{1}, R_{2}$, risers, $S T I$, solid tracer injection, $V_{1}, V_{2}, V_{3}$, valves

\section{TABLE 1}

Properties of Pall rings

\begin{tabular}{ll}
\hline$d_{\mathrm{p}}$ & $0015 \mathrm{~m}$ \\
$\delta$ & $0002 \mathrm{~m}$ \\
$a_{\mathrm{p}}$ & $310 \mathrm{~m}^{2} / \mathrm{m}^{3}$ \\
$\epsilon_{\mathrm{p}}$ & 086 \\
$N$ & $22 \times 10^{5} \mathrm{~m}^{-3}$ \\
\hline
\end{tabular}

Aur at ambient conditions was used as the gas phase and the solid phase was a highly porous catalyst carrier (class $A$ according to Geldart's powder classification [16]). The properties of the particles are summanzed in Table 2.

\section{Residence time distribution experiments in the gas phase}

Helium, which does not adsorb on the solid [17], was used as the tracer gas during the RTD experiments for the gas phase. The tracer was injected in the inlet distributor by means of a magnetic three-way valve which was switched for $0.1 \mathrm{~s}$ from carrier gas (air) to helium. The tracer concentration in the aur stream was detected with a flow-through catharometer. The latter was connected with the column via a $0.08 \mathrm{~m}$ long tube with an internal diameter of $5 \times 10^{-4} \mathrm{~m}$ to ensure a rapid response. The measured response time of the gas analysing system was much less than 1 second. To prevent particles from entering the catharometer the tube inlet was covered with a glass filter. The sample gas was continuously sucked from the column by means of a vacuum pump. Successive pulses were detected in the packing at a distance of $0.05 \mathrm{~m}$ from the inlet and outlet, $L_{1}$ and $L_{2}$ respectively.

\section{Solvd-phase dispersion measurements}

Solıd-phase dispersion has also been determined from RTD experiments. We used a colour technique to trace the particles. Part of the original white particles was coloured black with a diluted drawing ink solution. The particles were filtered off, dried in the air, and finally for $50 \mathrm{~h}$ in a fluid bed. The concentration of black particles was measured by a reflection technique. Figure 3 shows the specially designed reflectometer. The sample

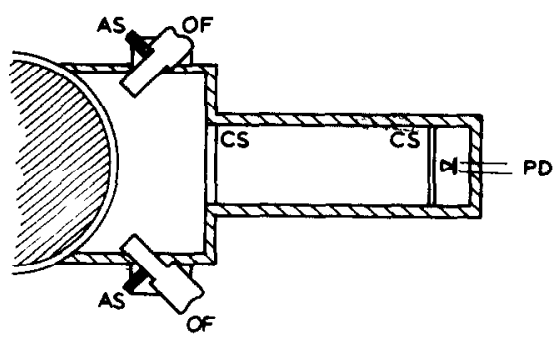

(a)

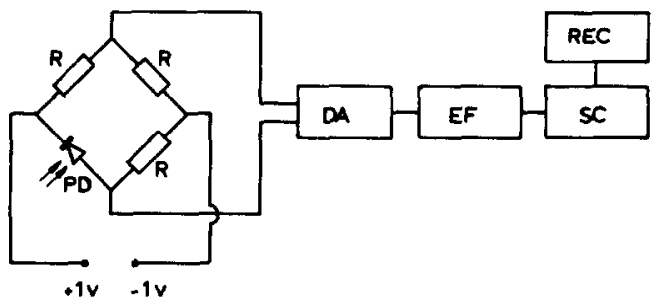

(b)

Fig 3. Reflectometer and electrical diagram (a) AS, adjusting screw for optical fibre, CS, collimating slit, OF, optical fibre for illumination, PD, photodiode (b) DA, differentıal amplifier, EF, electronic filter, PD, photodiode (BPX 94), $R$, resistance ( $R=$ $10 \mathrm{M} \Omega$ ), REC, recorder, SC, oscilloscope 
TABLE 2

Properties of the solid particles

Composition

Partıcle diameter distribution (sieve analysıs)

Diameter $\left(\times 10^{-6} \mathrm{~m}\right)$
$<44$
$44-75$
$75-105$
$105-150$
$150-210$
$210-300$
$<300$

87 wt \% $\mathrm{SlO}_{2}$

129 wt $\% \mathrm{Al}_{2} \mathrm{O}_{3}$

Wt \%

73

305

239

369

16

03

01

$\pm 70 \times 10^{-6} \mathrm{~m}$

$2200 \quad \mathrm{~kg} / \mathrm{m}^{3}$

$813 \mathrm{~kg} / \mathrm{m}^{3}$

$475 \quad \mathrm{~kg} / \mathrm{m}^{3}$

063

078
Cumulative wt \% 73

378

617

980

996

999

100

Mean particle diameter

Skeletal density

Fixed bed density*

Particle void fraction $\epsilon_{\text {part }}$

Fixed bed void fraction*

*Settled bed after fludization

was illuminated by a projector through two optical fibres to avoid heating the reflectometer by the light source. Reflected light reached a photodiode via two collımating slits of $3 \times 10^{-4} \mathrm{~m}$ each. Durng the tests, particles were collected in the Perspex section on valve $\mathrm{V}_{2}$ (see Fig. 2).

The reflectometer could be moved horizontally along the wall of this measuring section between valves $V_{2}$ and $V_{1}$. The photodiode was incorporated in a Wheatstone bndge circuit supplied with a stable $2 \mathrm{~V}$ source. The signal from the bridge entered a differential amplifier and an electronic filter to remove the $50 \mathrm{~Hz} \mathrm{AC}$ component from the light source. The signal was read from an oscilloscope or a recorder. This measuring system was found to be linear up to a concentration of $5 \%$ of black particles.

We designed a special solid tracer injector which is shown in Fig. 4. It consisted of four cylindrical containers which were inserted in a Perspex housing and interconnected by cogwheels. During the RTD measurements for the solid phase it was placed in the column between the disengaging zone and the packang (see Fig. 2). The tracer containers could be moved outside the injector, as shown in Fig. 4, where they were each filled with about $5 \times 10^{-4} \mathrm{~kg}$ of black particles and then replaced in the housing again. Here each container had a cover on top to prevent the white particles, which flowed through the injector, from enternng. By means of an external handle the containers were turned upside down and the black particles then entered the main solnd flow which passed a redistribution gnd to ensure good initial mixing with the tracer particles.

Applying this special construction the tracer was spread out over the whole area (plane injection), and was mixed with the feed. No pressure changes occurred and the injection time was small.

At the moment tracer injection took place, valve $\mathrm{V}_{2}$ was closed to collect solid on top of it. If the additional variance of the injection and collection section is sufficiently small the black-white distribution of the sample on top of valve $V_{2}$ will give the RTD of the solid. The concentration of black particles was measured by moving the reflectometer from $\mathrm{V}_{2}$ over the sample height. After each experiment the collected powder was removed from the system in the following way. Valve $\mathrm{V}_{2}$ contained a porous plate distributor. The sample could be fluidized with air entering by $I_{2}$. The fludized particles were sucked from the column through a tube which was connected to a waterjet pump. The solid particles were separated from the aur stream in a cyclone. Before each experiment a base line was measured after the section had been filled with white powder alone. 


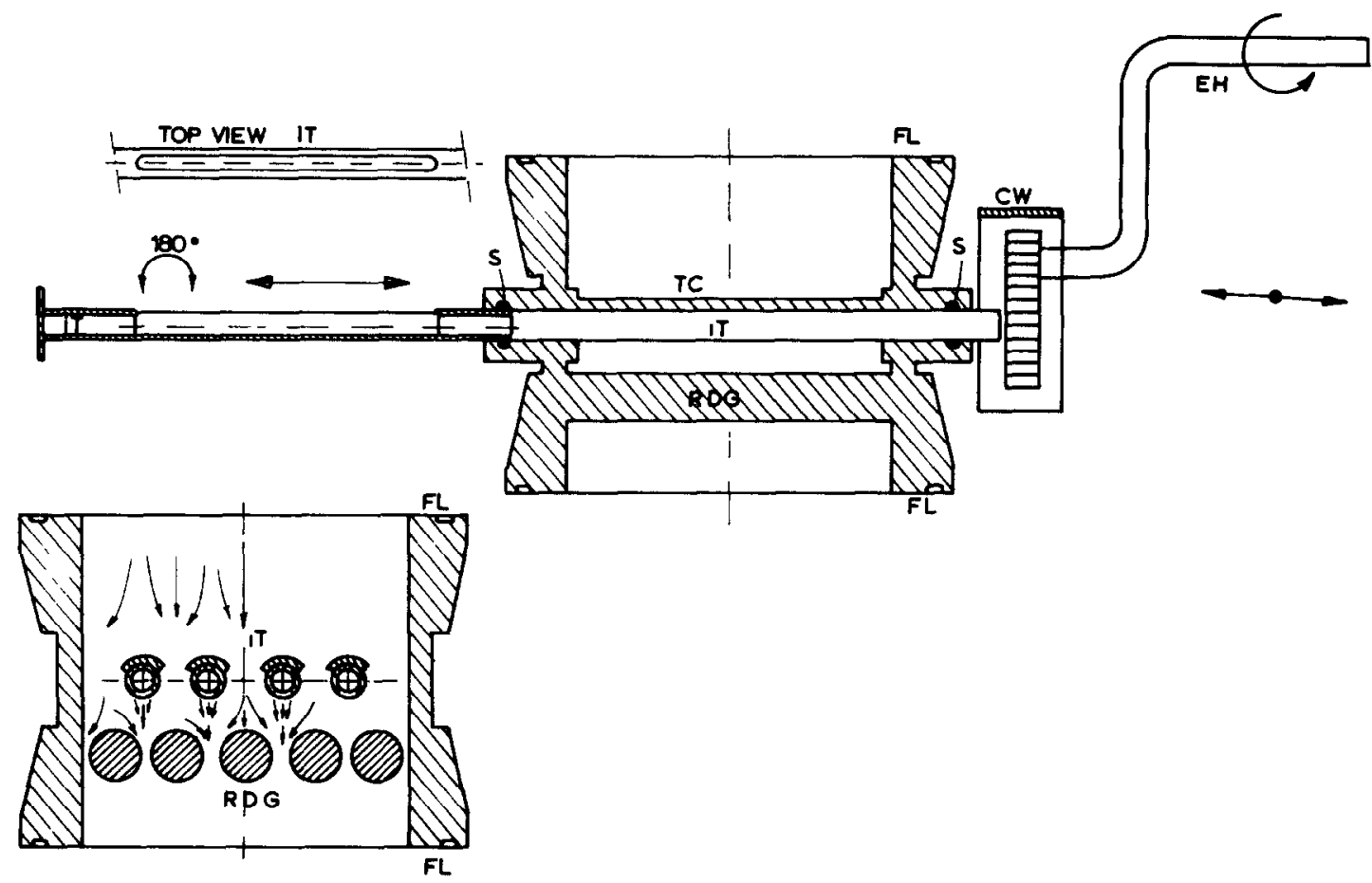

Fig 4 Injector for solıd tracer $\mathrm{CW}$, cogwheels, EH, external handle to turn the tracer containers upside down, FL, flange, IT, injection tube, RDG, redistribution gnd, S, seal, TC, cover of tracer container

\section{RESULTS}

\section{Dispersion of the gas phase}

The model parameters for the gas phase were evaluated using the various methods described previously. In Appendix B the criteria for the best fit and the $s$ - and $\omega$-intervals over which the fits were carried out are given. Table 3 presents the average results from the various methods at two different solid mass fluxes, the superficial gas velocity being varied. The Peclet numbers and mean residence times for the measuring section (see Fig. 1) were calculated from six input-output sets. The standard error is also given. The theoretical mean residence time was calculated according to eqn. (9).

$\tau_{\mathrm{g} \text { calc }}=\frac{\left[\epsilon_{\mathrm{p}}-\left(1-\epsilon_{\mathrm{part}}\right) \beta\right]\left(L_{2}-L_{1}\right)}{u_{\mathrm{g}}}$

At zero solid mass flux the different methods give almost the same results; the Peclet number is about 110 and is independent of the superficial gas velocity. The Bodenstein number for this case is 1.9. If the Bodenstein number is equal to 2 than the helght of one Pall ring layer corresponds to the height of a mixing unit $\left(=2 d_{p} / \mathrm{Bo}\right)$.
If the solid velocity is low, especially at low superficial gas velocities, the various parameter determination methods yield deviating results. At higher gas velocities (which are of practical interest) the differences are smaller. Large differences are caused by tailing. The method of moments around the ongin and the Laplace fit pay more attention to the tail of the experimental transfer function than other parameter determination techniques. The methods of Michelsen and $\varphi$ stergaard [13] and Gunn [15] and the frequencydomain fit account more for the general shape of the transfer function.

In countercurrent processes such as adsorptron this tailing will be less important because the slow fraction will be in equilibrium. For this reason we want to present here the results obtained with the frequency-domain fit. A more sophisticated companson of the various methods is beyond the scope of this article and is given elsewhere [18].

With the imperfect pulse technique it is not possible to compare an experimental RTD curve directly with the model curve in the time domain. Instead the expemmental transfer function in the time domain can be found from eqn. (5) by numencal inversion to 

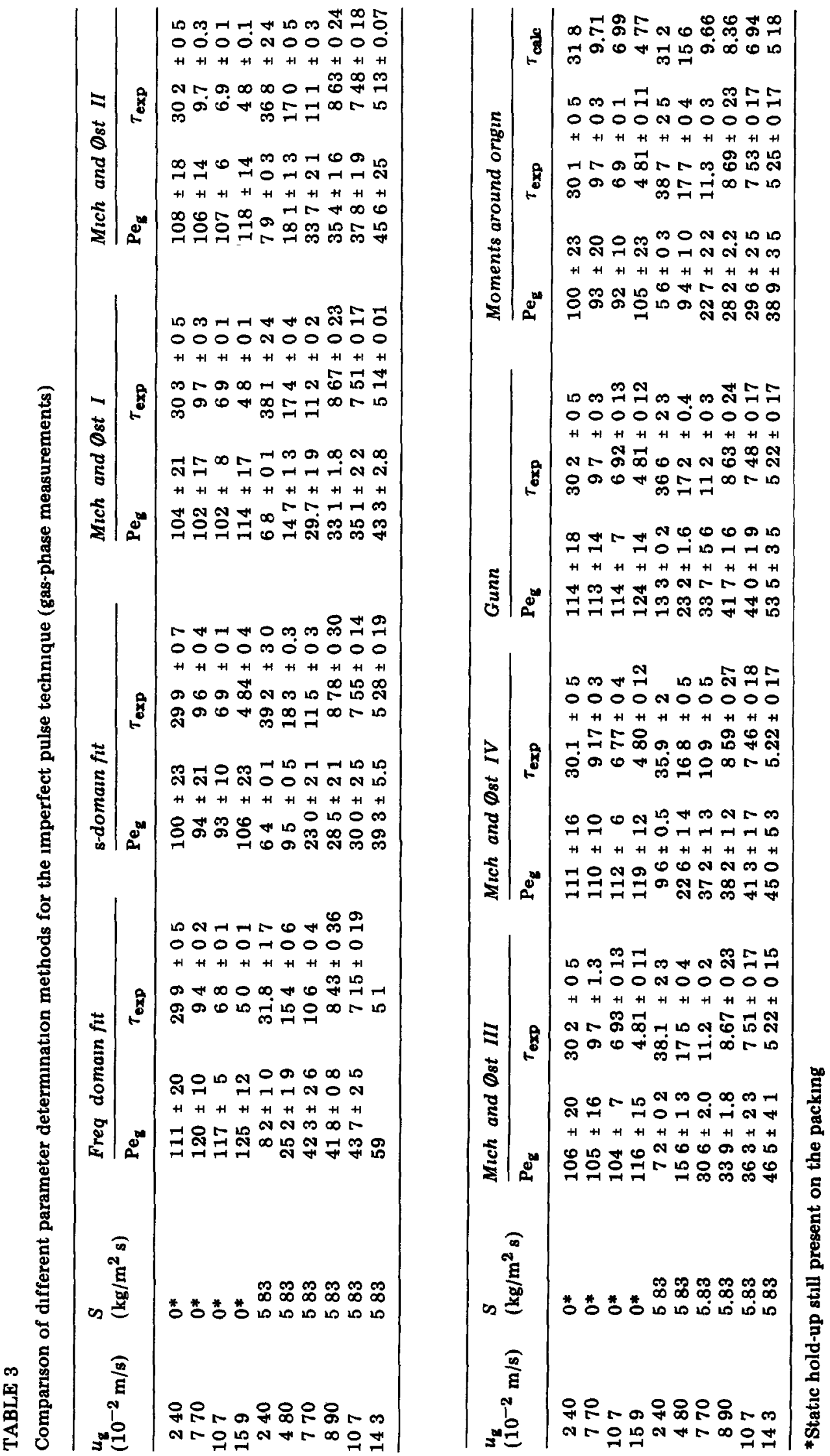
the time domain. Figure 5 compares the experimental transfer function with the model curve for a high and a low gas velocity.

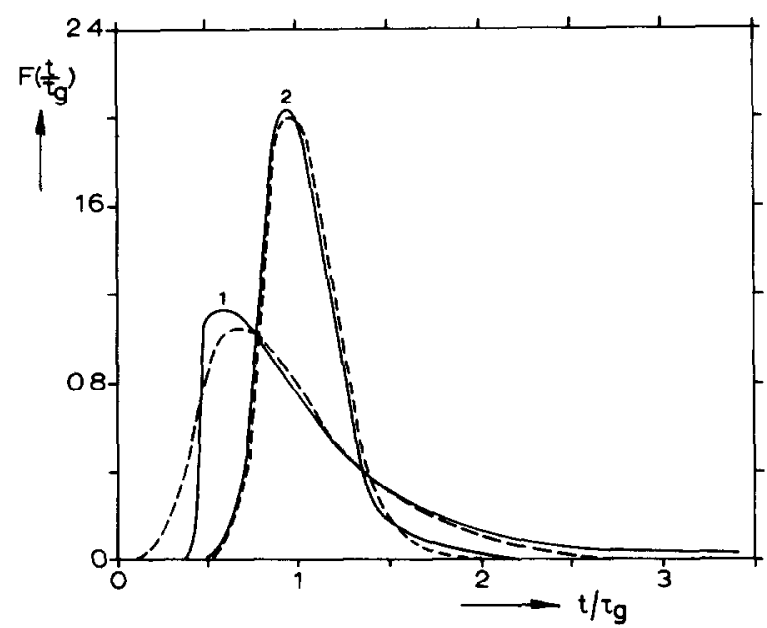

Fig 5 Dimensionless transfer functions in the time domain $S=583 \mathrm{~kg} / \mathrm{m}^{2} \mathrm{~s}$ Full curve, experimental, broken curve, best fit (frequency domain) Curve 1 $u_{\mathrm{g}}=0024 \mathrm{~m} / \mathrm{s}, P e_{\mathrm{g}}=836, \tau_{\mathrm{g}}=314 \mathrm{~s}$, curve 2 $u_{\mathrm{g}}=0143 \mathrm{~m} / \mathrm{s}, \mathrm{Pe}_{\mathrm{g}}=503, \tau_{\mathrm{g}}=488 \mathrm{~s}$

The model curves were calculated according to eqn. (A16) by inserting the optimal values from the frequency-domain fit. From Fig. 5 it can be seen that the agreement of the mathematical model with the experimental data is satisfactory for curve 2 (high gas velocity) while for curve 1 there is some tendency for tailing (low gas velocity).

In Fig. 6 the experimental mean residence time is plotted against the calculated values from eqn. (9). Deviations from the theoretical values were nearly always smaller than $5 \%$ and never larger than $11 \%$.

Figure 7 shows the Bodenstein number for the gas phase versus the superficial gas veloc1ty at different solid flow rates. Some typical results for a gas-liquid packed column at trickle flow are also given. At a given solid mass flux the Bodenstein number increases with increasing gas velocity. Near the flooding point large fluctuations in the observed Bodenstein number occur. All data he within the shaded area. In gas-liquid systems the Bodenstein number for the gas phase decreases with increasing gas velocity [19 21]. The disparity between gas-liquid systems and gas-solid systems is possibly caused by the fact that in gas-solid trickle flow the particles become more suspended in

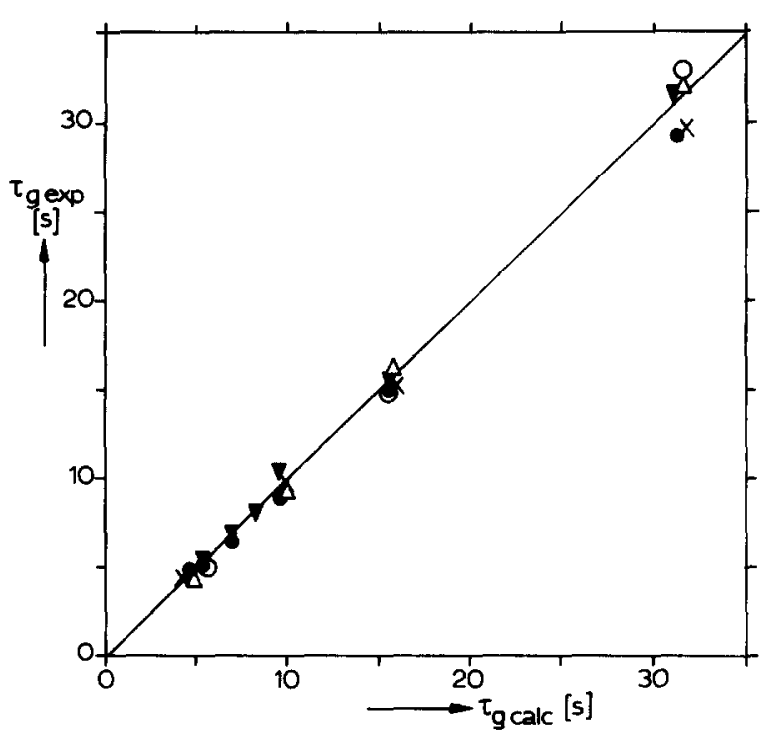

Fig 6 Experimental versus calculated mean residence time

$\begin{array}{ll}\text { Symbol } & S\left(\mathrm{~kg} / \mathrm{m}^{2} \mathrm{~s}\right) \\ \bullet & 000 \\ \circ & 0081 \\ \times & 123 \\ \triangle & 389 \\ \nabla & 583\end{array}$

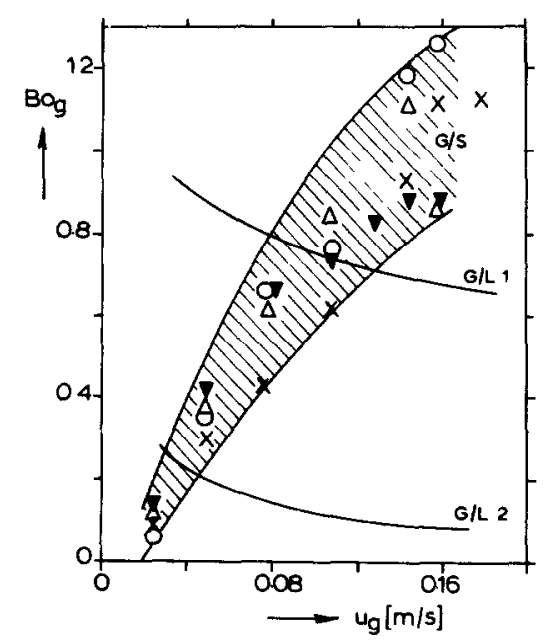

Fig 7. Bodenstein number for gas phase versus superficial gas velocity Symbols see Fig 6. Relations for gas-liquid systems (Raschıg rings, $d_{p}=00127 \mathrm{~m}$, liquid mass flux, $L=5 \mathrm{~kg} / \mathrm{m}^{2}$ s) curve 1 , De Maria and White [21], $\mathrm{Bo}_{\mathrm{g}}=24 \mathrm{Re}_{\mathrm{g}}^{-024} \times 10^{-0} \mathrm{O02L}$, curve, 2, Sater and Levenspiel $[20], \mathrm{Bo}_{\mathrm{g}}=$ $34 \mathrm{Re}_{\mathrm{g}}^{-0} 067 \times 10^{-0} 0026 \mathrm{~L}$

the gas phase at higher gas velocities [1], thus there will be less accessible area for gas flow.

The dispersion of the gas phase is strongly influenced by the flow of the particles, as can be seen from Fig. 8. Here the Bodenstein 


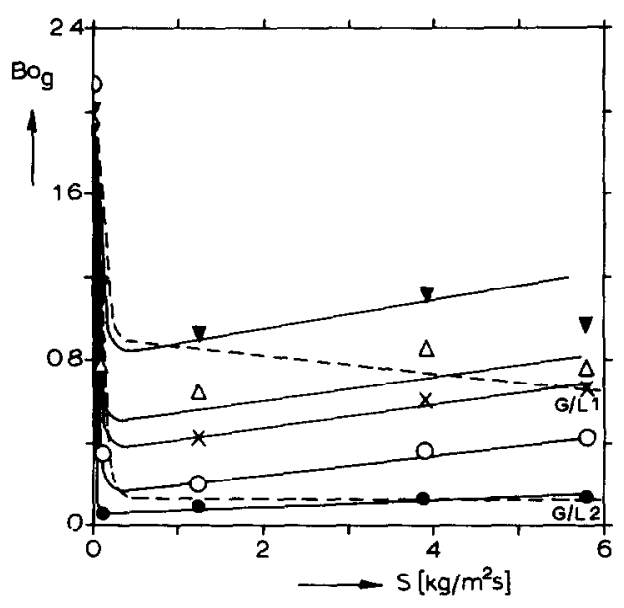

Fig 8 Bodenstein number of gas phase versus solıd mass flux Broken curve G/L 1, De Maria and White [21], broken curve G/L 2, Sater and Levensplel [20]. (Raschig rngs, $00127 \mathrm{~m}, u_{\mathrm{g}}=015 \mathrm{~m} / \mathrm{s}$ ) Symbol $u_{\mathrm{g}}(\mathrm{m} / \mathrm{s})$

- 0024

$\circ \quad 0048$

$\times \quad 0077$

$\triangle \quad 0107$

$\nabla \quad 0143$

number for the gas phase is plotted against the sold mass flux at different gas flow rates.

At zero solnd flow rate the Bodenstein number is about 2 . Only a very small particle flow, especially at low gas velocities, can drastically increase gas-phase dispersion. For practically important conditions, however (high gas and solid flow rates), the axıal dispersion of the gas phase is lower. Here 2 - 5 Pall ring layers are equivalent to the height of one mixıng unit. Consequently for longer columns the gas phase is almost in plug flow.

\section{Dispersion of the solid phase}

In contrast with the RTD measurements for the gas phase we assumed, for practical reasons, the solid tracer injection to be a perfect delta function. The time-domain solution for the response on a perfect delta function for closed-closed boundaries is given in Appendix A. Table 4 presents the average parameter values calculated from the time-domain optimization and from the moments around the origin [11]. For each value, three or four experiments were used; the standard error is also given. The average solid hold-up is calculated from eqn. (10):

$\beta=\frac{S \tau_{s}}{\rho_{\text {pert }} L}$
Table 4 also presents the experimental hold-up which was measured in an independent way described in an earlier paper [1]. Table 4 gives a picture analogous to that of Table 3. At a low solid mass flow flux the two methods give different results while at high $S$ values the deviations are less serious. Again this is caused by the fact that the model does not represent the physical reality well enough at a low solid mass flux.

In this region there is some tendency to tailing resulting in a lower Peclet number for the method of moments around the ongin. This can also be seen from Fig. 9 where experimental response curves for both a low solid mass flux and a high $S$ value are plotted. The theoretical response curves are calculated from eqn. (A11) by inserting the $\mathrm{Pe}_{\mathrm{s}}$ and $\tau_{\mathrm{s}}$ values found from the time-domain optimization.

From Table 4 and Fig. 9 it can be concluded that the dispersed plug-flow model with closed-closed boundary conditions fits the experimental data reasonably well but tailing occurs at low solid mass fluxes. Results presented in this paper were calculated with the time-domain optimization technique.

In Fig. 10 the expenmental hold-up is plotted against the calculated hold-up. Two experimental hold-up lines are shown, one including the permanent fraction of the static hold-up, being that fraction of the static hold-up that does not drain off the packing even after vibration of the column for $10 \mathrm{~mm}$ [1], and the second excluding this contmbution.

From Fig. 10 it is clear that the permanent fraction of the static hold-up does not exchange with the other particles and consequently may be considered to be part of the packing.

In Fig. 11 the Bodenstein number for the solid phase is plotted against the superficial gas velocity, the solid mass flux being vaned.

As in gas-liquid systems the Bodenstein number is almost independent of the gas flow rate and also increases with solid flow rates. Near the flooding point the dispersion in the solid phase is increasing, as shown by the broken line. Figure 12 is a cross-plot of Fig. 11. Here the Bodenstein number for the solid phase is plotted against the solid mass flux. Nearly all the data lie in the shaded area.

Results for gas-liquid systems are also presented. The absolute value of the Boden- 


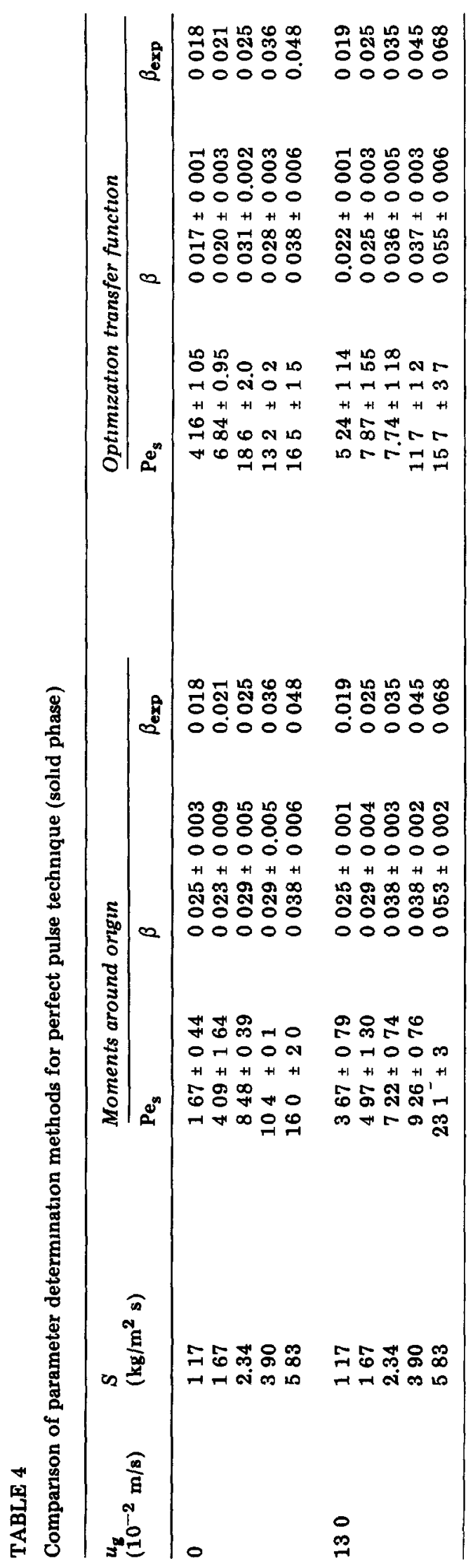




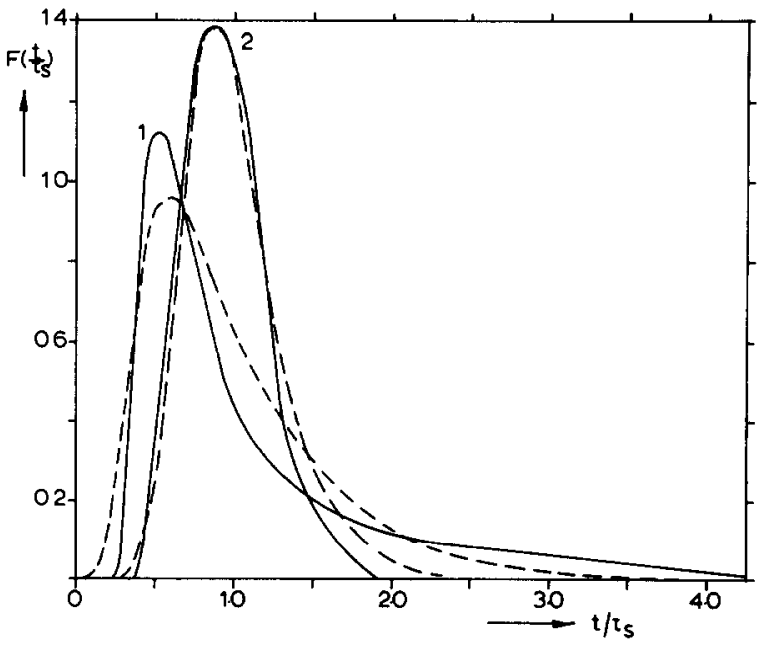

Fig 9 Dimensionless response curves for solid phase Full curve, experimental, broken curve, best fit (obtained by time-domain optımization) Set $1 S=$ $117 \mathrm{~kg} / \mathrm{m}^{2} \mathrm{~s}, \mathrm{Pe}_{\mathrm{g}}=399, u_{\mathrm{g}}=0 \mathrm{~m} / \mathrm{s}$ Set $2 \mathrm{~S}=$ $583 \mathrm{~kg} / \mathrm{m}^{2} \mathrm{~s}, \mathrm{Pe}_{\mathrm{g}}=183, u_{\mathrm{g}}=013 \mathrm{~m} / \mathrm{s}$

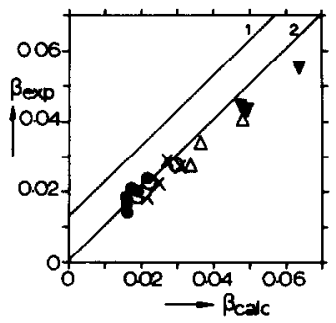

Fig 10 Calculated solid hold-up versus expenmental hold-up Curve 1, including permanent solid hold-up, curve 2, without permanent solid hold-up

$\begin{array}{ll}\text { Symbol } & S(\mathbf{k g} \\ - & 117 \\ & 167 \\ \times & 234 \\ \triangle & 390 \\ \nabla & 583\end{array}$

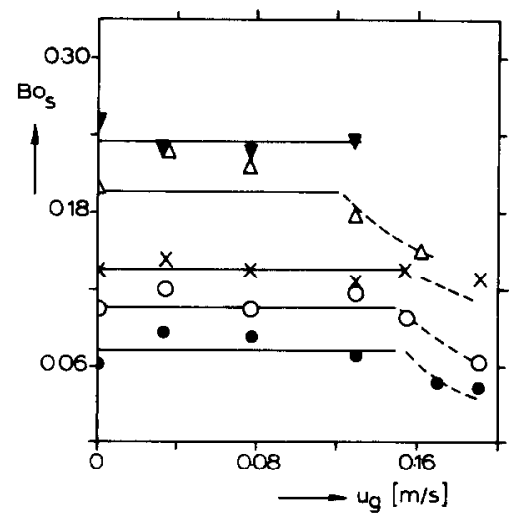

Fig 11 Rodanstein number for solid phase versus superficial gas velocity Symbols see Fig 10

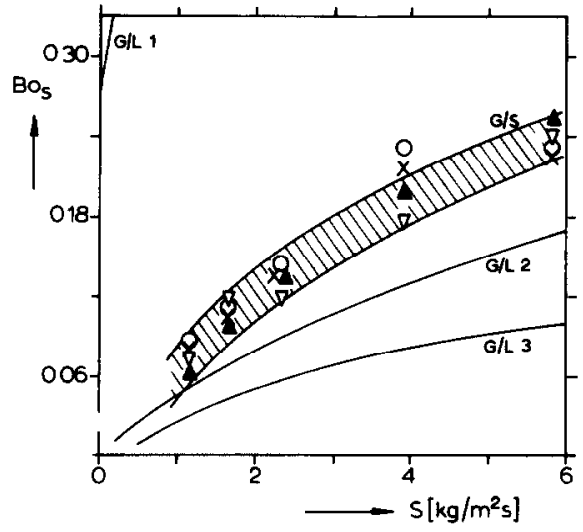

Fig 12 Bodenstein number for solid phase versus solid mass flux

$\begin{array}{ll}\text { Symbol } & u_{\mathrm{g}}(\mathrm{m} / \mathrm{s}) \\ 0 & 0.033 \\ \nabla & 0130 \\ \times & 0078 \\ \Delta & 0\end{array}$

Gas-liquid systems (water, Raschig rings $00127 \mathrm{~m}$ ) curve 1, Furzer and Michell [23], $\mathrm{Bo}_{\mathrm{L}}=$ $13 \mathrm{Re}_{\mathrm{L}}^{0}{ }^{4} \mathrm{Ga}^{-1 / 3}$, curve $2, \mathrm{Bo}_{\mathrm{L}}=00758 \mathrm{Re}^{-0.703}$ curve 3, van Swaai] et al [22], graphical correlation, wettable packıng (non-wettable, $\mathrm{Bo}_{\mathrm{L}}=05-2$ )

stein number for the liquid phase in gasliquid systems varies considerably. This can be related to the different wettabilities of the various packings $[19,22]$. From Fig. 12 it is clear that the Bodenstein number for the solid phase exhibits the same trend as the Bodenstein number for the liquid phase in gasliquid systems [22, 23]. For practical conditions the axial dispersion of the solid phase is low and the height of a mixing unit corresponds to 5 - 15 Pall ring layers.

\section{CONCLUSIONS}

Axıal dispersion in the gas and solid phases of a gas-solid packed column at trickle flow has been evaluated. Axıal dispersion of the gas phase is strongly influenced by the flow of solid matter: if there is no solid flow the Bodenstein number is about 2 as can be expected, but it becomes a factor 10-20 lower at very low solid flow rates.

The axial dispersion of the solid phase is approximately independent of gas velocity except near flooding, where it increases slightly. The Bodenstein number for the solid 
phase increases with increasing solid mass flux.

For practical conditions, 2 - 5 and $5-15$ Pall ring layers correspond to the herght of a mixing unit in the gas and solid phase, respectively.

A new injection and detection system for RTD measurements in a continuous solid flow-through system has been developed. Th1s system works satisfactorily.

Different parameter determination methods for the axially dispersed plug-flow model from RTD measurements have been compared for both the "perfect pulse method" and the "imperfect pulse method". At low velocities of either phase, the various methods yield deviating results; these differences decrease if the velocity is increased. It is suggested that this effect is caused by the fact that the mathematical model does not describe the physical phenomena truthfully at low velocities (tailing).

\section{ACKNOWLEDGMENTS}

The authors wish to thank DSM for financial support during the present investigation. We are also much indebted to $\mathrm{Dr}$ G. van Straten who made the computer programs for the parameter optimization in the frequency domain.

\section{APPENDIX A}

\section{Mathematical expressions}

Boundary conditions for eqn. (1)

The boundary conditions for eqn. (1) are (see, for example, ref. 10):

closed-closed for dispersion (solid phase)

$C\left(0^{-}, \theta\right)=C\left(0^{+}, \theta\right)-\left.\frac{1}{\mathrm{Pe}_{\mathrm{s}}} \frac{\partial C(\theta)}{\partial \xi}\right|_{\xi=0^{+}}$

$C\left(0^{-}, \theta\right)=\delta(\theta)$

$-\left.\frac{1}{\mathrm{Pe}_{\mathrm{s}}} \frac{\partial C(\theta)}{\partial \xi}\right|_{, \xi=1}=0$

$C\left(1^{-}, \theta\right)=C\left(1^{+}, \theta\right)$ open-open for dispersion (gas phase)

$$
\begin{gathered}
C\left(0^{-}, \theta\right)-\left.\frac{1}{\mathrm{Pe}_{\mathrm{g}}} \frac{\partial C(\theta)}{\partial \xi}\right|_{\xi=0^{-}}= \\
C\left(0^{+}, \theta\right)-\left.\frac{1}{\mathrm{Pe}} \frac{\partial C(\theta)}{\partial \xi}\right|_{\xi=0^{+}} \\
C\left(0^{-}, \theta\right)=C\left(0^{+}, \theta\right)=f(\theta) \\
C\left(1^{-}, \theta\right)-\left.\frac{1}{\mathrm{Pe}_{\mathrm{g}}} \frac{\partial C(\theta)}{\partial \xi}\right|_{\xi=1^{-}}= \\
C\left(1^{+}, \theta\right)-\left.\frac{1}{\operatorname{Pe}_{\mathrm{g}}} \frac{\partial C(\theta)}{\partial \xi}\right|_{\xi=1^{+}}
\end{gathered}
$$

$C\left(1^{-}, \theta\right)=C\left(1^{+}, \theta\right)$

\section{Definition of the moments}

The $n$th weighted moment is defined by [13] :

$M_{n, s}=\int_{0}^{\infty} t^{n} \mathrm{e}^{-s t} C(t) \mathrm{d} t$

If $s=0$ then (A9) reduces to the $n$th moment around the ongin [11] :

$M_{n, 0}=\int_{0}^{\infty} t^{n} C(t) \mathrm{d} t$

Solutions for dispersed plug-flow model with closed-closed boundaries for dispersion

The time-domain solution for the response to a perfect delta function has been given by Otake and Kuniguta [9] (see also ref. 10):

$$
\begin{aligned}
F\left(\frac{t}{\tau_{\mathrm{s}}}\right)= & \exp \left[\frac{\mathrm{Pe}}{2}\left(1-\frac{t}{2 \tau_{\mathrm{s}}}\right)\right] \times \\
& \times \sum_{n=1}^{\infty} \frac{\delta_{n}\left(\mathrm{Pe}_{\mathrm{s}} \sin \delta_{n}+2 \delta_{n} \cos \delta_{n}\right)}{\delta_{n}^{2}+\left(\frac{\mathrm{Pe}_{\mathrm{s}}}{2}\right)^{2}+\mathrm{Pe}_{\mathrm{s}}} \times \\
& \times \exp \left(-\frac{\delta_{n}^{2}}{\mathrm{Pe}_{\mathrm{s}}} \frac{t}{\tau_{\mathrm{s}}}\right)
\end{aligned}
$$

where $\delta_{n}$ is given by the $n$th root of the transcendental equation

$\operatorname{cotg} \delta=\frac{\delta}{\mathrm{Pe}_{\mathrm{s}}}-\frac{\mathrm{Pe}_{\mathrm{s}}}{4 \delta}$ 
Expressions for the moments around the ongin have been given by van der Laan [11] . For the mean residence time he derived

$\tau_{\mathrm{s}}=\frac{M_{1,0}}{M_{0,0}}$

and, for the dimensionless vanance,

$$
\begin{aligned}
\sigma^{2} & =\frac{M_{2,0} M_{0,0}}{M_{1,0}^{2}}-1 \\
& =\frac{2}{\mathrm{Pe}_{\mathrm{s}}}-\frac{2}{\mathrm{Pe}_{\mathrm{s}}^{2}}\left[1-\exp \left(-\mathrm{Pe}_{\mathrm{s}}\right)\right]
\end{aligned}
$$

Solutıons for dispersed plug-flow model with open-open boundaries for dispersion

(a) Transfer functions The expression for the transfer function in the Laplace domain is given by Michelsen and $\varphi$ stergaard [13] ·

$\vec{F}(s)=\exp \left\{\frac{\mathrm{Pe}_{\mathrm{g}}}{2}\left[1-\left(1+\frac{4 s \tau_{\mathrm{g}}}{\mathrm{Pe}_{\mathrm{g}}}\right)^{1 / 2}\right]\right\}$

The transfer function in the time domain can be obtained by inverse Laplace transformation of eqn. (A15) (van Straten, prive communication)

$F\left(\frac{t}{\tau_{g}}\right)=\left(\frac{\mathrm{Pe}_{\mathrm{g}} \tau_{\mathrm{g}}^{3}}{4 \pi t^{3}}\right)^{1 / 2} \exp \left[-\frac{\mathrm{Pe}_{\mathrm{g}}}{4 t / \tau_{\mathrm{g}}}\left(1-\frac{t}{\tau_{\mathrm{g}}}\right)^{2}\right]$

Putting $s=j \omega$ in eqn. (A15) and separating the real and imagnary parts, Clements arrived at the complex transfer function [14]:

$f(\jmath \omega)=\operatorname{Re}_{\hat{F}}+\mathrm{JIm}_{\hat{F}}$

where

$$
\begin{aligned}
\operatorname{Re}_{\hat{f}}= & \exp \left\{\frac{P \mathrm{e}_{\mathrm{g}}}{2}\left[1-\left(A^{2}+1\right)^{1 / 4} \cos B\right]\right\} \times \\
& \times \cos \left[\frac{\mathrm{Pe}}{2}\left(A^{2}+1\right)^{1 / 4} \sin B\right]
\end{aligned}
$$

and

$$
\begin{aligned}
\operatorname{Im}_{\hat{F}}= & \exp \left\{\frac{P e_{\mathrm{g}}}{2}\left[1-\left(A^{2}+1\right)^{1 / 4} \cos B\right]\right\} \times \\
& \times \sin \left[-\frac{P e_{\mathrm{g}}}{2}\left(A^{2}+1\right)^{1 / 4} \sin B\right]
\end{aligned}
$$

$A$ and $B$ are given by

$A=\frac{4 \omega \tau_{\mathrm{g}}}{\mathrm{Pe}_{\mathrm{z}}}$ and

$B=1 / 2 \operatorname{arctg} A$

(b) $P e_{g}$ and $\tau_{g}$ from the weighted moments. From eqn. (A9) it follows that

$$
\begin{aligned}
M_{n, s} & =\int_{0}^{\infty} t^{n} C(t) \mathrm{e}^{-s t} \mathrm{~d} t \\
& =(-1)^{n} \frac{\mathrm{d}^{n}}{\mathrm{~d} s^{n}}(\bar{C}(s))
\end{aligned}
$$

where

$\bar{C}(s)=\int_{0}^{\infty} C(t) \mathrm{e}^{-s t} \mathrm{~d} t$

$\bar{C}(s)$ is the Laplace transformed normalized signal at the detection.

The experimental points of the transfer function may be calculated according to

$\bar{F}(s)=\frac{\vec{C}_{\text {out }}(s)}{\bar{C}_{\text {in }}(s)}=\frac{M_{0, s} \text { lout }}{\left.M_{0, s}\right|_{\text {in }}}$

Michelsen and $\varphi$ stergaard introduced the following functions [13]:

$U_{0}(s)=\ln \bar{F}(s)=\ln M_{0 . s} \stackrel{\text { out }}{\text { in }}$

$U_{1}(s)=-\frac{1}{\bar{F}(s)} \frac{\mathrm{d} \bar{F}(s)}{\mathrm{d} s}=\frac{M_{1, s}}{M_{0, s}}{\underset{\text { in }}{\text { out }}}^{\text {out }}$

and

$$
\begin{aligned}
U_{2}(s) & =\frac{1}{\bar{F}(s)} \frac{\mathrm{d}^{2} \bar{F}(s)}{\mathrm{d} s^{2}}-\left[\frac{1}{\bar{F}(s)} \frac{\mathrm{d} \bar{F}(s)}{\mathrm{d} s}\right]^{2} \\
& =\left[\frac{M_{2, s}}{M_{0, s}}-\left(\frac{M_{1, s}}{M_{0, s}}\right)^{2}\right] \underset{\text { in }}{l_{\text {out }}}
\end{aligned}
$$

From eqns. (A15), (A22) and (A25) - (A27) it can be shown that

$$
\begin{aligned}
& U_{0}(s)=\frac{\mathrm{Pe}_{\mathrm{g}}}{2}\left[1-\left(1+\frac{4 s \tau_{\mathrm{g}}}{\mathrm{Pe}_{\mathrm{g}}}\right)^{1 / 2}\right] \\
& U_{1}(s)=\frac{\tau_{\mathrm{g}}}{\left(1+4 s \tau_{\mathrm{g}} / \mathrm{Pe}_{\mathrm{g}}\right)^{1 / 2}}
\end{aligned}
$$

and

$$
U_{2}(s)=\frac{2 \tau_{\mathrm{g}}^{2}}{\mathrm{Pe}_{\mathrm{g}}\left(1+4 s \tau_{\mathrm{g}} / \mathrm{Pe}_{\mathrm{g}}\right)^{3 / 2}}
$$

$\mathrm{Pe}_{\mathrm{g}}$ and $\tau_{\mathrm{g}}$ can be calculated in a number of ways. 
Michelsen and $\varphi$ stergaard I. the moments $M_{0, s}$ and $M_{1, s}$ are calculated, using a fixed $s-$ value, and are inserted in (A25) and (A26).

Now $\mathrm{Pe}_{\mathrm{g}}$ and $\tau_{\mathrm{g}}$ can be obtained from (A31) and (A32)

$\mathrm{Pe}_{\mathrm{g}}=\frac{U_{0}\left(U_{0}+2 s U_{1}\right)}{U_{0}+s U_{1}}$

and

$\tau_{\mathrm{g}}=\frac{-U_{0} U_{1}}{U_{0}+2 s U_{1}}$

Michelsen and $\emptyset$ stergaard II: the moments $M_{0, s}, M_{1, s}$ and $M_{2, s}$ are calculated at a fixed $s$-value. $P e_{\mathrm{g}}$ and $\tau_{\mathrm{g}}$ can be calculated from eqns. (A26), (A27) and (A33), (A34):

$\mathrm{Pe}_{\mathrm{g}}=\frac{2 U_{1}^{2}}{U_{2}}\left(1-\frac{2 s U_{2}}{U_{1}}\right)^{1 / 2}$

$\tau_{\mathfrak{z}}=U_{1}\left(1-2 \frac{s U_{2}}{U_{1}}\right)^{-1 / 2}$

If $s=0$, then the weighted moments are reduced to the moments around the ongin:

$$
\begin{aligned}
\mathrm{Pe}_{\mathrm{g}} & =\frac{2 U_{1}^{2}}{U_{2}} \\
& =2\left\{\left(\frac{M_{1,0}}{M_{0,0}}\right)^{2}\left[\frac{M_{2,0}}{M_{0,0}}-\left(\frac{M_{1,0}}{M_{0,0}}\right)^{2}\right]^{-1}\right\} \underset{\text { in }}{\text { out }}
\end{aligned}
$$

and

$\tau_{\mathrm{g}}=U_{1}=\frac{M_{1,0}}{M_{0,0}} \prod_{\text {in }}^{\text {out }}$

These expressions are the same as those obtained by Aris [6].

Michelson and $\varphi$ stergaard III (graphical or numerical): the transfer function is calculated for different values of $s$, and $U_{0}$ is evaluated v1a (A25). Equation (A28) may be rearranged to give

$-\frac{1}{U_{0}(s)}=-\frac{1}{\mathrm{Pe}_{\mathrm{g}}}+\tau_{\mathrm{s}} \frac{s}{U_{0}^{2}(s)}$

A plot of $1 / U_{0}(s)$ versus $s / U_{0}^{2}(s)$ should yield a straight line with an intercept $-1 / \mathrm{Pe}_{\mathrm{g}}$ and slope $\tau_{\mathbf{g}}$.

Michelsen and $\emptyset_{\text {stergaard IV (graphical or }}$ numencal): $M_{0, \text { and }} M_{1, \text { are determined for }}$ different $s$-values, and $U_{1}$ evaluated from eqn. (A26); (A29) is rearranged to give
$\frac{1}{U_{1}^{2}}=\frac{1}{\tau_{\mathrm{g}}^{2}}+s \frac{4}{\tau_{\mathrm{g}} \mathrm{Pe}_{\mathrm{q}}}$

A plot of $1 / U_{1}^{2}(s)$ versus $s$ should give a stranght line with slope $4 / \tau_{\mathrm{g}} \mathrm{Pe}_{\mathrm{g}}$ and intercept $1 / \tau_{\mathrm{g}}^{2}$.

Method of Gunn [15] (graphical or numencal): for small $s$-values the square root in eqn. (A28) may be approximated by

$\left(1+\frac{4 s \tau_{\mathrm{g}}}{\mathrm{Pe})_{\mathrm{g}}}\right)^{1 / 2} \simeq 1+\frac{2 s \tau_{\mathrm{g}}}{\mathrm{Pe}_{\mathrm{g}}}-\frac{1}{8}\left(\frac{4 s \tau_{\mathrm{g}}}{\mathrm{Pe})_{\mathrm{g}}}\right)^{2} \mathrm{O}\left(s^{3}\right)$

By inserting (A39) in (A28) and rearranging, (A40) can be obtained.

$\frac{1}{s} U_{0}(s)=-\tau_{\mathrm{g}}+\frac{\tau_{\mathrm{z}}^{2}}{\mathrm{Pe}_{\mathrm{g}}} s+\mathrm{O}\left(s^{2}\right)$

If $U_{0}(s) / s$ is plotted against $s$, one should obtain a straight line on the interval $0<$ $4 \tau_{\mathrm{g}} s / \mathrm{Pe}_{\mathrm{g}}<0.2-0.4$ with slope $\tau_{\mathrm{g}}^{2} / \mathrm{Pe}_{\mathrm{g}}$ and intercept $-\tau_{\mathbf{g}}$.

\section{APPENDIX B}

Fit criteria and fit intervals

The best fit was accomplished if the sum of the least squares between data and model was minimal. The mathematical formulation of this criterion is given by the minimum of the goal functions (B1 - B3):

\section{time domain}

$\sum_{1}^{N}\left[F\left(\frac{t}{\tau}\right)-F_{\exp }\left(\frac{t}{\tau}\right)\right]^{2}$

s-domain

$\sum_{1}^{N}\left[\bar{F}(s)-\bar{F}_{\exp }(s)\right]^{2}$

frequency domain

$$
\begin{array}{r}
\sum_{1}^{N}\left[\left(\operatorname{Re}_{\hat{F}(j \omega)}-\operatorname{Re}_{\hat{F}_{\text {exp }}(j \omega)}\right)^{2}+\right. \\
\left.+\left(\operatorname{Im}_{\hat{F}(j \omega)}-\operatorname{Im}_{\hat{F}_{\text {exp }}(j \omega)}\right)^{2}\right]
\end{array}
$$

The model parameters for Michelsen and $\emptyset$ stergaard's methods I and II have been determined at $s=1 / \tau_{\mathrm{s}}[13]$. Michelsen and $\varphi$ stergaard [13] showed by a noise analysis that 
the value of $s$ for the third and the fourth methods should lie in the interval

$\frac{0.4}{\tau_{\mathrm{g}}}<s<\frac{3}{\tau_{\mathrm{g}}}$

The $\omega$-value always ranged from zero to the frequency at which the experimental transfer function began to oscillate.

\section{NOMENCLATURE}

$a_{\mathfrak{p}} \quad$ surface area of packıng per cubic metre of column, $\mathrm{m}^{2} / \mathrm{m}^{3}$

$A$ constant defined in eqn. (A20)

$B$ constant defined in (A21)

Bo Bodenstein number defined in eqns.

(2) and (3)

$C$ normalized concentration

$d_{\mathfrak{p}} \quad$ normal packıng diameter, $\mathrm{m}$

$D \quad$ dispersion coefficient, $\mathrm{m}^{2} / \mathrm{s}$

$f(\theta) \quad$ signal at first detection point for gasphase RTD experiments

$F\left(t / \tau_{\mathbf{s}}\right)$ response on a delta function (eqn. (A11))

$F\left(t / \tau_{\mathrm{g}}\right)$ transfer function in time domain (eqn. (A16))

$\bar{F}(s) \quad$ transfer function in $s$ domain defined by eqn. (4)

$\hat{F}(j \omega)$ transfer function in frequency domain defined by eqn. (5)

$\mathrm{Ga} \quad\left(=d_{\mathrm{p} g}^{3} g \rho_{\mathrm{L}}^{2} / \eta_{\mathrm{L}}^{2}\right)$ Gallleo number for liquid phase of gas-liquid systems

$\operatorname{Im}_{\hat{F}} \quad$ Imaginary part of complex transfer function (eqn. (A19))

J $\quad \sqrt{ }-1$

$L \quad$ column length, $\mathrm{m}$

$L_{1} \quad$ distance of first measuring point from inlet, $\mathbf{m}$

$L_{2} \quad$ distance of second measurng point from inlet, $m$

$M_{n, 8} \quad n$th welghted moment defined in eqn. (A9)

$N$ number of Pall rings per cubic metre of column, $\mathrm{m}^{-3}$

$\mathrm{Pe}_{\mathrm{g}} \quad\left(=\mathrm{Bo}_{\mathfrak{g}}\left[L_{2}-L_{1}\right] / d_{\mathfrak{p}}\right)$, Peclet number for gas phase

$\mathrm{Pe}_{\mathrm{s}} \quad\left(=\mathrm{Bo}_{\mathrm{s}} L / d_{\mathfrak{p}}\right)$, Peclet number for solıd phase

$\mathrm{Re}_{\hat{F}} \quad$ real part of complex transfer function (eqn. (A18))

$\operatorname{Re}_{\mathrm{L}} \quad\left(=\rho_{\mathrm{L}} u_{\mathrm{L}} d_{\mathrm{p}} / \eta_{\mathrm{L}}\right)$, Reynolds number for liquid phase (gas-liquid systems)
$S$ solıd mass flux, $\mathrm{kg} / \mathrm{m}^{2} \mathrm{~s}$

$t$ time, $s$

$u$ superficial velocity, $\mathrm{m} / \mathrm{s}$

$U_{0} \quad$ function defined by eqn. (6)

$U_{1} \quad$ function defined by eqn. (7), $\mathrm{s}$

$U_{2} \quad$ function defined by eqn. (8), $\mathrm{s}^{2}$

Greek symbols

$\beta \quad$ hold-up of solıd phase (volume of particles/volume of column)

$\delta \quad$ wall thickness of ring, $m$

$\delta(\theta)$ perfect delta function

$\delta_{n} \quad n$th root of transcendental function (eqn. (A12))

$\epsilon_{\mathrm{p}} \quad$ vold fraction of packing

$\epsilon_{\text {part }} \quad$ vold fraction of particle

$\xi$ dimensionless length coordinate

$\rho_{\text {part }}$ particle density, $\mathrm{kg} / \mathrm{m}^{3}$

$\tau \quad$ mean residence time, $s$

$\theta$ dimensionless time $(\theta=t / \tau)$

$\omega$ frequency, $\mathrm{s}^{-1}$

\section{Subscripts}

calc calculated

exp experimental

g gas phase

L liquid phase of gas-liquid systems

s solid phase

\section{Superscripts}

- Laplace transformed variable

- Founer transformed variable

\section{REFERENCES}

1 A $W$ M. Roes and W P $M$ van Swaay, Chem Eng $J, 17(1979) 81$

$2 \mathrm{~T}$ Miyauchı and $\mathrm{T}$ Vermeulen, Ind Eng. Chem Fundam., 2 (1963) 113

$3 \mathrm{~J}$ C Mecklenburg and S Hartland, The Theory of Backmixing, Wiley-Interscience, London, 1975.

4 A W M. Roes and W P M van Swaaj, Chem Eng $J, 18$ (1979) 29

50 Levenspiel, Chemical Reaction Engineering, 2nd edn , Wiley, New York, 1972

6 R Aris, Chem Eng Sct, 9 (1959) 9.

7 K. B Bischoff, Chem Eng Sct, 12 (1960) 69.

8 K B Bischoff, Can $J$ Chem Eng, 41 (1963) 129

9 T. Otake and E. Kunıguta, Kagaku Kogaku, 22 (1958) 144

$10 \mathrm{C}$ Y. Wen and L T. Fan, Models for Flow Systems and Chemical Reactors, Marcel Dekker, New York, 1975 
11 E Th van der Laan, Chem Eng. Scl, 7 (1958) 187

12 Y P Abbi and D J Gunn, Trans Inst Chem Eng , 5 (1976) 225

$13 \mathrm{M}$ L Michelsen and $\mathrm{K}$ Фstergaard, Chem Eng $\mathrm{Scl}, 25$ (1970) 583

14 W C Clements, Chem Eng Scl, 29 (1969) 957

15 D J Gunn, Chem Eng Sct, 25 (1970) 56

16 G Geldart, Powder Technol, 7 (1973) 285

$17 \mathrm{~W}$ Bohle and $\mathrm{W} P \mathrm{M}$ van Swaay, Proc 2nd Int Conf Flutd, Cambridge Univ Press, 1978
18 A W M Roes, Thesis, Twente Unıversity of Technology, 1978

19 W P M van Swaay, Thesis, Eindhoven University of Technology, 1967

20 V A Sater and O Levenspiel, Ind Eng Chem Fundam , 5 (1966) 144

21 F De Maria and R R. White, AIChE J, 6 (1960) 473.

22 W $P$ Man Swaaij, J C Charpentier and J Villermaux, Chem Eng Sct, 24 (1969) 1083

23 I A Furzer and $\mathrm{R}$ W Michell, AIChE J, 16 (1970) 380 